International Journal of Linguistics, Literature and Culture
Available online at https://sloap.org/journals/index.php/ijllc/
Vol. 7, No. 6, November 2021, pages: 489-498
$\begin{aligned} & \text { ISSN: 2455-8028 } \\ & \text { https://doi.org/10.21744/ijllc.v7n6.1968 }\end{aligned}$

\title{
Pragmatic Analysis of Racial Humor in Online Discourse
}

Taghreed Abdulasalam ${ }^{\text {a }}$ Istqlal Hassan Ja'afar ${ }^{\text {b }}$

Article history:

Submitted: 27 September 2021

Revised: 18 October 2021

Accepted: 03 November 2021

\section{Keywords:}

humor;

online discourse;

racial jokes;

superiority humor;

superiority resolution;
CrossMark

\begin{abstract}
The present paper aims to investigate how racial humor is triggered in racial jokes posted online. Racial jokes and the ways it is triggered is an underresearched topic in comparison to the quickly developing literature about other types of racist language. Thus, one of the main problems this thesis attempt to address is English as a Lingua Franca (ELF) users' potential lack of awareness of the racially sensitive issues and how to deal with them in (online) intercultural communication. The paper analyzes (312) racial jokes, collected from eight different racial Joke accounts on Twitter. After in-depth reading and a systematic coding process of the dataset, three types of racial jokes were distinguished. These are superiority-based triggers, incongruitybased triggers, and blended triggers. These three different types were found to perform two different functions: racial stereotype reinforcement and racial stereotype challenge.
\end{abstract}

International journal of linguistics, literature and culture () 2021. This is an open access article under the CC BY-NC-ND license (https://creativecommons.org/licenses/by-nc-nd/4.0/).

\section{Corresponding author:}

Taghreed Abdulasalam,

Mustansirya University, Baghdad, Iraq.

Email address: totaaliroro1993@gmail.com

${ }^{a}$ Mustansirya University, Baghdad, Iraq

${ }^{\mathrm{b}}$ Mustansirya University, Baghdad, Iraq 


\section{Introduction}

Ritchie (2005), defines a joke as a relatively brief text that, for a certain cultural association its basic purpose, the performing of a distracted reaction within its readers/hearers, and that is usually repeatable in a widespread range of conditions. Within the domain of linguistics, "jokes" make use of linguistic ambiguity and there seems to be a frame of jokes which recognizes itself not by actions or events, but by particular linguistic traits or features of language for their effect. Hughes (2002), defines racial jokes as an effective device of social effect, which enhances not solely order in societies but also social hierarchies. Racial jokes regard sensitive issues since they are used to avoid offending others, when using humor or when they want to socially bond with other (native) speakers of English.

In this context, the paper aims to advance the understanding of how racial humor can be triggered in an online intercultural setting. In this context, one of the main problems this thesis address in English is a Lingua Franca (ELF) users' potential lack of awareness of the racially sensitive issues and how to deal with them in (online) intercultural communication. The paper attempts to answer the following research questions:

1) How racial humor on Twitter is triggered?

2) What functions does online racial humor serve?

\section{Theories of verbal humor}

Verbal humor is a linguistic phenomenon that has always been considered an interesting topic for scholarly research. Many theories have been proposed to account for verbal humor. Three main theories of humor foreground different aspects of humor. These are:

1) Superiority-based trigger revolves around the idea that laughter expresses emotions of superiority over other people or a former state of ourselves. A contemporary pioneer of this theory is Roger Scruton, who investigates amusement as an "attentive demolition" of a person or something joined with a person. "If people dislike being laughed at.... It is certainly because laughter lessens its object in the subject's eyes", (Scruton, 1986). Morreal (1983), points out that "the Superiority Theory" is one of the basic and famous humor theories. Based on such theory, humor can be viewed as an utterance of individuals' emotions of superiority over others. From a historical perspective, Morreal makes it obvious that superiority theory belongs to Plato, (427-347 BC), who mentioned that the task of humor originates from the foolish and wicked nature of humans. Plato believed that self-ignorance is what a person laughable.

2) Relief Theory: According to the "Release Theory of Humor", people make humor because they think that pressure is condensed by doing so, (Azeez \& Turki, 2019). This type of theory is concentrated basically on the grantee of humor, or more particularly, on the psychological impacts humor causes in the recipient. Thus, humor is "one of the so-called substitution mechanisms" that make one convert his socially tabooed aggressive tempos to accept individuals and thus prevent wasting extra mental energy suppressing them, (Krikmann, 2006).

3) Incongruity resolution can be viewed through shifting the sense of the source from the widespread meaning to a novel and unexpected one (Steen, 2007). In this respect, Marin-Arrese (2008), points out that incongruity can be considered as a conflict between the interpretative, frequent, or direct meaning and a shift, unpopular, and more implicit meaning that leads to the re-interpretation of the funny utterance. Particularly, incongruity grows from the flouting of the speech expectation, emotion of tension, absence of coherence, co-existence of two clashing thoughts, or frames of source, forming a mismatch between the predicted content and real utterance, (Miller, 2009).

\section{The pragmatics of verbal humor}

Richards \& Schmidt (2013), point out that pragmatics deals with "the study of the use of language in communication, particularly the relationships between sentences and the contexts and situations in which they are used". From an interactional perspective, humor is produced to serve certain functions. Hay (2000), postulates three major functions for humor in discourse; these are: "solidarity, power and psychological needs". Such functions are performed by means of different linguistic devices and interactional techniques. Understanding the meaning of jokes and realizing their interactional functions in discourse requires an understanding how implicit meaning is produced, 
communicated, and recognized. The concept of implicature provides such an understanding. According to Hurford et al. (2007), implicature is a concept of utterance meaning as opposed to sentence meaning. It is related to the method by which speakers work out the indirect illocutions of utterances. In his theory of implicature, Grice (1989), produces the Cooperative Principle (CP), which subsumes four conversational maxims. The CP and its maxims are considered to be the basis for successful communication. Blutner \& Zeevat (2004), argue that these four maxims are considered the rules for conversations. People try their best to follow these maxims and suppose their conversational partner to follow. The maxims express a rational basis and not mere conventions (Grice, 1975; Herring, 2007; Howe, 2002).

Ariel (2002), adds that Gricean four maxims explicate the application of the cooperative principle. These conversational maxims are:

1) Quantity: The category of Quantity relates to the quantity of information to be provided and under which fall the following maxims:

- Make your contribution as informative as is required (for the current purpose of the exchange).

- Do not make your contribution more informative than is required.

2) Quality: Try to make your true contribution one.

- Do not say what you believe to be false.

- Do not say that for which you lack adequate evidence.

3) Relation:

- Be relevant.

4) Manner:

Be obvious in your manner. It has to do with how something should be said.

- Avoid ambiguous expressions.

- Avoid vagueness by all means. -Be short (avoid unnecessary prolixity).

- Create a sense of order. (Grice, 1989)

\section{Materials and Methods}

The selection of the tweets was first informed by discourse-centered online ethnography which combines the systematic observation of selected sites of online discourse (Curry \& Dunbar, 2013; Vaid et al., 2003). Based on this approach, eight different Twitter accounts specialized in racial humor were selected. All the tweets posed on these accounts were collected using vicinitas.io, which is an online software to track hashtags, tweets, and followers. This software makes the collected corpus eligible for more in-depth pragmatic investigation and insightful corpus-assisted analysis, such as word clouds, concordance, and collocation as shown in the table below. The methodological approach used in this paper is predominantly qualitative, due to the international nature of the pragmatic phenomena explored in the thesis, i.e., racial stereotyping and humor. The analytical framework employed in the analysis will draw on triggering racial humor, as introduced by Weaver (2011), and Attardo \& Raskin (2017). The analysis, in this respect, will distinguish between superiority-based triggers, blended triggers, and incongruity resolution-based triggers.

Table 1

Information of concerned accounts

\begin{tabular}{lllllllll}
\hline & $\begin{array}{l}\text { Account } \\
1\end{array}$ & $\begin{array}{l}\text { Account } \\
2\end{array}$ & $\begin{array}{l}\text { Account } \\
3\end{array}$ & Account 4 & Account 5 & Account 6 & Account 7 & Account 8 \\
\cline { 2 - 8 } $\begin{array}{l}\text { Name of } \\
\text { Account }\end{array}$ & $\begin{array}{l}\text { @ Racist } \\
\text { Jokes }\end{array}$ & $\begin{array}{l}\text { @ Racist } \\
\text { JokesEN }\end{array}$ & $\begin{array}{l}\text { @ Racial } \\
\text { Jokes }\end{array}$ & @ blackjokes & $\begin{array}{l}\text { @ HaHa_ } \\
\text { Blackjokes }\end{array}$ & $\begin{array}{l}\text { @ TheFnnyRacie } \\
\text { st }\end{array}$ & $\begin{array}{l}\text { @ TheFunny } \\
\text { Racest }\end{array}$ & $\begin{array}{l}\text { @ TheFunny } \\
\text { Racists }\end{array}$ \\
\hline $\begin{array}{l}\text { No. of } \\
\text { Tweets }\end{array}$ & 43 & 18 & 86 & 7 & 7 & 102 & 4 & 17 \\
$\begin{array}{l}\text { No. of } \\
\text { Retweets } \\
\text { No. of }\end{array}$ & 61 & 6 & 3 & 16 & 44 & 3 & 0 & 49 \\
\hline
\end{tabular}

Abdulasalam, T., \& Ja'afar, I. H. (2021). Pragmatic analysis of racial humor in online discourse. International Journal of Linguistics, Literature and Culture, 7(6), 489-498. https://doi.org/10.21744/ijllc.v7n6.1968 


\begin{tabular}{|c|c|c|c|c|c|c|c|c|}
\hline \multicolumn{9}{|c|}{ Followers } \\
\hline $\begin{array}{l}\text { No. of } \\
\text { Likes }\end{array}$ & 105 & 28 & 4 & 5 & 54 & 14 & 0 & 55 \\
\hline $\begin{array}{l}\text { No. of } \\
\text { Replies }\end{array}$ & 5 & 2 & 0 & 2 & 2 & 3 & 1 & 4 \\
\hline $\begin{array}{l}\text { No. of } \\
\text { Quotes }\end{array}$ & 0 & 0 & 0 & 1 & 0 & 0 & 0 & 0 \\
\hline
\end{tabular}

\section{Data analysis}

Based on the coding process and in-depth analysis of the dataset, three types of racial jokes triggers were identified. These were superiority-based triggers, incongruity resolution-based triggers and blended triggers. The racial jokes were actually filtered manually by extracting only racial jokes and excluding comments, posts and tweets.

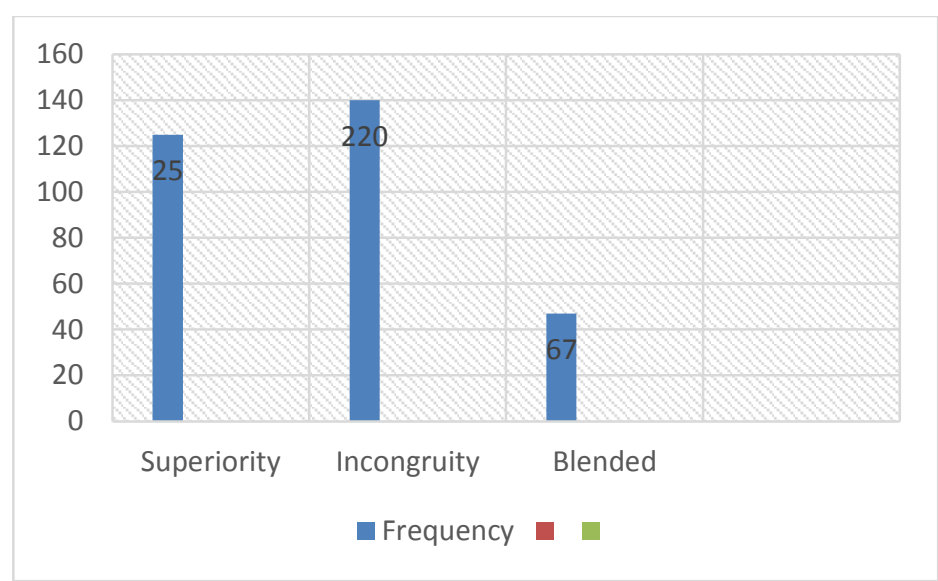

Figure 1. Forms of racial jokes

Thus, the total number of the identified racial jokes was (312). The incongruity-based triggers scored (220) tokens, representing the highest frequency, whereas superiority-based triggers marked (25). Finally, blended triggers scored the lowest with (67) tokens. To exemplify how these different types of triggers gave rise to racial jokes, the three next sections will provide three examples for each type of trigger (Hübler \& Bell, 2003; Song et al., 2021). The section below exemplifies these three different types of humor triggers.

\section{1) Superiority-based triggers}

There are many instances of racial jokes given in the dataset involving the use of superiority-based triggers. One of them can be represented via the following tweet:

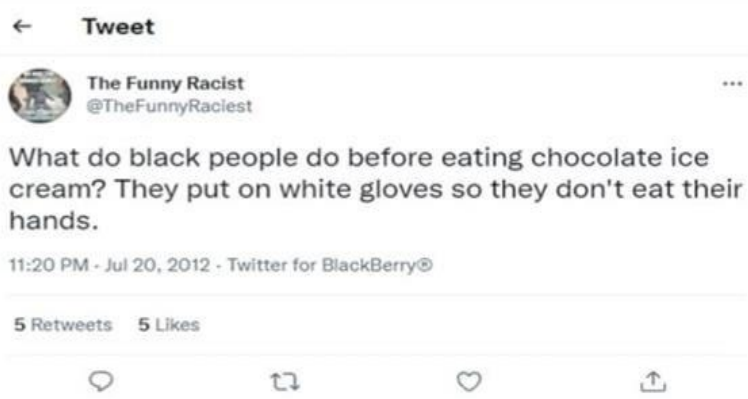

Figure 2. An example of a joke 
The joke showed in Figure (2) revolves around the difference between white and black people by showing that back people lack manners and are uncultured. The maker of the joke above wants to express his/her feelings of superiority over the black people. Such behavior is highlighted by Scruton (1986), who suggests that "If people dislike being laughed at..... It is certainly because laughter lessens its object in the subject's eyes". The joke poster makes up of the set-up part represented by "What do black people do before eating chocolate ice cream?" and the punchline part represented by "They put on white gloves so they don't eat their hands". This highlights the joke maker's disparaging of black. He makes fun of their eating habits by showing how uncultivated black people are, that they could confuse their hands and chocolate ice cream and at the same time the joke maker makes fun of the color of their skin matching it to chocolate ice cream. The joke maker communicates this implicature using flouting the maxim of relevance. Additionally, the usage of racial jokes can also be useful in the sense that it strengthens the mixture of relationships between social associations and social attitudes through the employment of jokes (Lebowitz et al., 2011; Jeder, 2015; Meza et al., 2018).

\section{2) Incongruity resolution-based triggers}

Consider the following example:

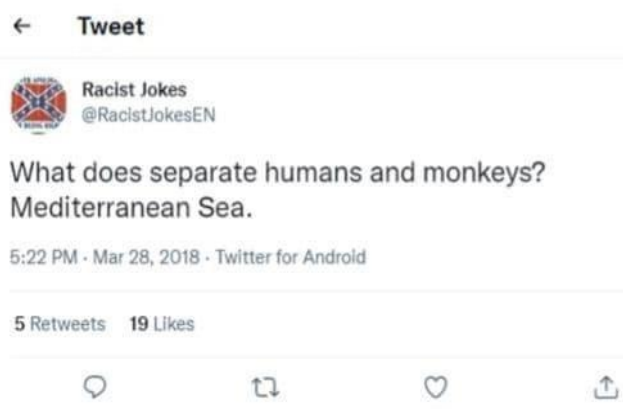

Figure 3. An example of a joke

The above tweet is derived from @ RacistJokesEN whose account history and information are stated earlier. The sample above represents an obvious instance of racial jokes triggered by incongruity resolution. This joke consists of the set-up, i.e. What does separate humans and monkeys? and the punchline parts, i.e. Mediterranean Sea. The joke maker employs two inconsistent conceptions, i.e. humans and monkeys in the set-up part, and Mediterranean Sea in the punchline. Thus, the salient meaning of the concerned joke is abandoned in favor of implicit and unexpected but contextually appropriate one (Zabalbeascoa, 2005; Weisfeld, 1993; Athilakshmi \& Chitra, 2018).

On this ground, the form of racial joke makes a conflict between the interpretative meaning represented by humans and monkeys and unpopular meaning realized by Mediterranean Sea. In this case, the sense leads to the reinterpreting the funny joke. Additionally, incongruity form in this joke occurs as a result of the existing two clashing thoughts simultaneously or the mismatch between the predicted content and real utterance, (Miller, 2009). This gives rise to the implicature that humans and monkeys can be differentiated from Mediterranean Sea. Thus, the joke maker communicates this implicature using flouting the maxim of relevance

\section{3) Blended triggers}

Blended triggers combine both superiority-based triggers and incongruity resolution-based triggers. That is, the concerned type of racial joke has a sense of superiority and contradictory meanings at the same time. The following instance is chosen from the account of @ RacialjokEN: 


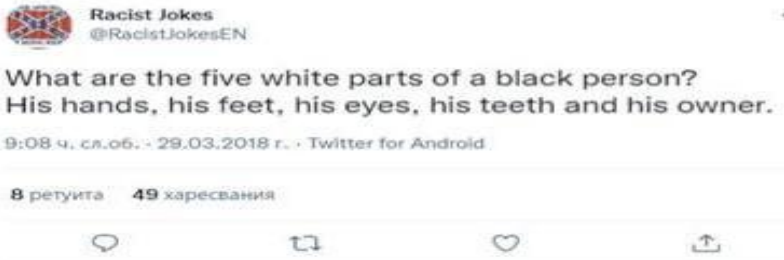

Figure 4. An example of a joke

The current tweet includes a mixture of racial joke forms. From a superiority-based triggers perspective, the joke poster, being a white person, intends to express his emotions of superiority over the black people. Again, this behavior is affirmed by many scholars, like (Jensen, 2018), who explicate that the superiority theory does not only refer to the inclusion of shortcomings in others like an aspect of humor but also illuminate the mixture of relations between social associations and social perspectives through the usage of jokes in a way that makes black followers feel inferior. As for incongruity resolution-based trigger, the joke maker combines two paradoxical conceptions. To illustrate, the black people have five white things, i.e. hands, feet, eyes, teeth, and owner although they have black skin (Bressler \& Balshine, 2006; Ramachandran, 1998). So, he makes the present racial jokes depending on the inconsistency between the different body parts of a black person and his/her owner. As a result, the combination of the two triggers, i.e. superiority and incongruity-resolution, produces a new form of racial joke known as blended form. It is worth mentioning that the concerned joke consists of the set-up part represented by what are the five parts of a black person and the punchline part which represents the black people have five white things, i.e. hands, feet, eyes, teeth, his owner.

\section{Functions of racial humor on Twitter}

Based on an in-depth analysis of the dataset and comments and replies generated by the followers of the investigated Twitter accounts, it was found that the jokes identified in the dataset could serve two main functions, namely: stereotype reinforcing and stereotype challenging. The researcher will elaborate on each one of these functions, providing an example for each function in the sub-sections below:

- Stereotype Reinforcing Jokes

In the context of this analysis, this function focuses on reinforcing the dominant racial stereotype about the superiority of the white community in addition to belittling the target, i.e. black American community. This can be evident in the following comment:

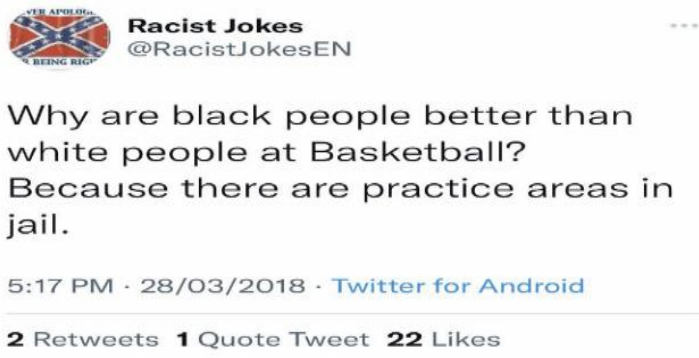

Figure 5. An example of a joke 


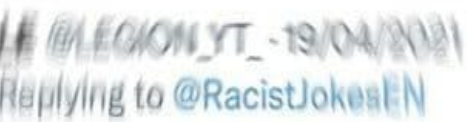

This shit too funny

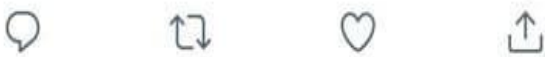

Figure 6. An example of a comment

The reinforcing function of racial jokes can be observed via the above sample. The commenter mentions that "this shit too funny" in response to the joke" Why are black people better than white people at Basketball? Because there are practice areas in jail", which is shown in figure (5) above. It is reflected that the commenter tends to target out-group members through using the word "shit" representing black people as inferior ones compared with white people.

- Stereotype Challenging Jokes

The following comment showcases this stereotype challenging function:

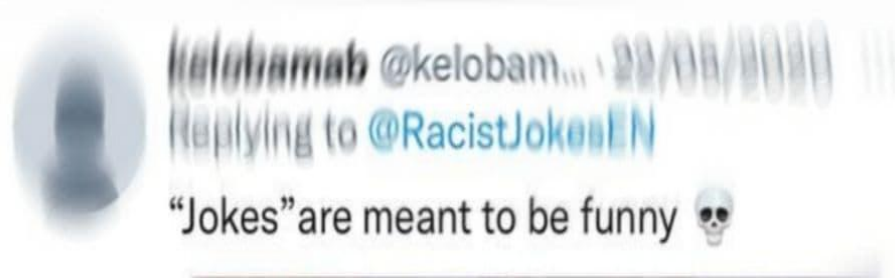

Figure 7. An example of a comment

Here, the commenter states that "jokes" are meant to be funny" as a response to "what are the five parts of black person? the black people have five white things, i.e. his hands, his feet, his eyes, his teeth, and his owner" to reflect protesting and challenging in a society. It is claimed that some racial jokes formed by certain owners' accounts are just to be funny and entertaining. That is, racial jocks may carry some instructions respectfully and entertainingly to suggest suitable solutions for certain issues. Thus, this function of racial jokes urged many followers to interact with each other and reduce self-identification within a racial association as well as strengthen cultural and social connections.

\section{Conclusion}

Three forms of racial jokes can be distinguished in the data in question. These are superiority-based triggers, incongruity-based triggers, and blended triggers. Incongruity-based triggers were found to be the most frequently used trigger in the dataset, whereas blended triggered were found to be the least commonly used in the dataset. It was found that racial humor on Twitter could serve two functions: racial stereotype reinforcing or racial stereotype challenging. The racial stereotype reinforcing function enhances intergroup solidarity and social cohesion, targeting out-group members, depicting them as inferior to those belonging to the group of the joke maker. As for the racial stereotype challenging function, racial jokes were found to be used non-derogatorily to raise awareness of the racial biases and prejudices in a light-spirited manner. Such non- derogatorily uses of racial jokes aim to challenge the racial stereotypes prevalent in society.

\section{Conflict of interest statement}

The authors declared that's they have no competing interest.

Abdulasalam, T., \& Ja'afar, I. H. (2021). Pragmatic analysis of racial humor in online discourse. International Journal of Linguistics, Literature and Culture, 7(6), 489-498. https://doi.org/10.21744/ijllc.v7n6.1968 
Statement of authorship

The authors have a responsibility for the conception and design of the study. The authors have approved the final article.

Acknowledgments

We are grateful to two anonymous reviewers for their valuable comments on the earlier version of this paper. 


\section{References}

Ariel, M. (2002). The demise of a unique concept of literal meaning. Journal of pragmatics, 34(4), 361-402. https://doi.org/10.1016/S0378-2166(01)00043-1

Athilakshmi, V., \& Chitra, S. (2018). College student attitude towards social media. International Research Journal of Management, IT and Social Sciences, 6(1), 33-41. https://doi.org/10.21744/irjmis.v6n1.481

Attardo, S., \& Raskin, V. (2017). Linguistics and humor theory. In The Routledge handbook of language and humor (pp. 49-63). Routledge.

Azeez, A. P. F. H., \& Turki, M. N. A. (2019). Humor and Translation. ADAB AL-BASRAH, (88).

Blutner, R., \& Zeevat, H. (2004). Editors' introduction: pragmatics in Optimality Theory. In Optimality theory and pragmatics (pp. 1-24). Palgrave Macmillan, London.

Bressler, E. R., \& Balshine, S. (2006). The influence of humor on desirability. Evolution and Human Behavior, 27(1), 29-39. https://doi.org/10.1016/j.evolhumbehav.2005.06.002

Curry, O. S., \& Dunbar, R. I. (2013). Sharing a joke: The effects of a similar sense of humor on affiliation and altruism. Evolution and Human Behavior, 34(2), 125-129. https://doi.org/10.1016/j.evolhumbehav.2012.11.003

Grice, H. P. (1975). Logic and conversation. In Speech acts (pp. 41-58). Brill.

Grice, P. (1989). Studies in the Way of Words. Harvard University Press.

Hay, J. (2000). Functions of humor in the conversations of men and women. Journal of pragmatics, 32(6), 709-742.

Herring, S. C. (2007). A faceted classification scheme for computer-mediated discourse. Language@ internet, 4(1).

Howe, N. E. (2002). The origin of humor. Medical hypotheses, 59(3), 252-254. https://doi.org/10.1016/S03069877(02)00209-8

Hübler, M. T., \& Bell, D. C. (2003). Computer-mediated humor and ethos: Exploring threads of constitutive laughter in online communities. Computers and Composition, 20(3), 277-294. https://doi.org/10.1016/S87554615(03)00036-7

Hughes, M. K. (2002). Through the looking glass: Racial jokes, social context, and the reasonable person in hostile work environment analysis. S. Cal. L. Rev., 76, 1437.

Hurford, J., Heasley, B., \& Smith, M. (2007). Semantics a Course Book. New York.

Jeder, D. (2015). Implications of using humor in the classroom. Procedia-Social and Behavioral Sciences, 180, 828833. https://doi.org/10.1016/j.sbspro.2015.02.218

Jensen, T. W. (2018). Humor as interactional affordances: An ecological perspective on humor in social interaction. Psychology of Language and Communication, 22(1), 238-259.

Krikmann, A. (2006). Contemporary linguistic theories of humour. Folklore: Electronic journal of folklore, (33), 2758.

Lebowitz, K. R., Suh, S., Diaz, P. T., \& Emery, C. F. (2011). Effects of humor and laughter on psychological functioning, quality of life, health status, and pulmonary functioning among patients with chronic obstructive pulmonary disease: A preliminary investigation. Heart \& Lung, 40(4), 310-319. https://doi.org/10.1016/j.hrtlng.2010.07.010

Marín-Arrese, J. I. (2008). Cognition and culture in political cartoons.

Meza, A. K. T., Freyre, J. R. A., Cevallos, M. G. O., \& Pico, M. J. M. (2018). Autonomy, Good Humor and Support Networks, Potential of Community Resilience Intervention in People Victims of the Earthquake in the Calderón Parish. International Research Journal of Management, IT and Social Sciences, 5(1), 1-8. Retrieved from https://sloap.org/journals/index.php/irjmis/article/view/23

Miller, K. E. L. (2009). The Unuttered Punch Line: Pragmatic Incongruity and the Parsing of "What's the Difference" Jokes.

Morreall, J. (1983). Taking laughter seriously. Albany, NY: State University of New York.

Ramachandran, V. S. (1998). The neurology and evolution of humor, laughter, and smiling: the false alarm theory. Medical hypotheses, 51(4), 351-354. https://doi.org/10.1016/S0306-9877(98)90061-5

Richards, J. C., \& Schmidt, R. W. (2013). Longman dictionary of language teaching and applied linguistics. Routledge.

Ritchie, D. (2005). Frame-shifting in humor and irony. Metaphor and Symbol, 20(4), 275-294.

Scruton, R. (1986). Laughter in the philosophy of laughter and humor. John Morreall (ed.), Albany: State University of New York Press, pp. 156-171.

Song, K., Williams, K. M., Schallert, D. L., \& Pruitt, A. A. (2021). Humor in multimodal language use: Students' Response to a dialogic, social-networking online assignment. Linguistics and Education, 63, 100903. https://doi.org/10.1016/j.linged.2021.100903

Abdulasalam, T., \& Ja'afar, I. H. (2021). Pragmatic analysis of racial humor in online discourse. International Journal of Linguistics, Literature and Culture, 7(6), 489-498. https://doi.org/10.21744/ijllc.v7n6.1968 
Steen, G. (2007). Finding metaphor in grammar and usage: A methodological analysis of theory and research (Vol. 10). John Benjamins Publishing.

Vaid, J., Hull, R., Heredia, R., Gerkens, D., \& Martinez, F. (2003). Getting a joke: The time course of meaning activation in verbal humor. Journal of Pragmatics, 35(9), 1431-1449. https://doi.org/10.1016/S03782166(02)00184-4

Weaver, S. (2011). Jokes, rhetoric and embodied racism: a rhetorical discourse analysis of the logics of racist jokes on the internet. Ethnicities, 11(4), 413-435.

Weisfeld, G. E. (1993). The adaptive value of humor and laughter. Ethology and sociobiology, 14(2), 141-169. https://doi.org/10.1016/0162-3095(93)90012-7

Zabalbeascoa, P. (2005). Humor and translation-an interdiscipline. 